\title{
Game-Based Learning in Tertiary Education: A New Learning Experience for the Generation $\mathrm{Z}$
}

\author{
Ding Ding, Chong Guan, and Yinghui Yu
}

\begin{abstract}
Game-based learning pedagogy has received widespread attention in recent years due to its conceivable potential in adapting to the evolving needs from the "Net Generation", or "digital natives". Due to difficulties in defining, constructing and measuring complex variables as well as the subsequent results, however, rigorous empirical research on the effectiveness of gamification in education or game-based learning has been limited, especially in tertiary education.

In this research, we investigate the effectiveness of game-based learning as an instructional strategy for tertiary education. Particularly, we conducted a semi-structured survey in a finance class, where an online stock trading game was implemented. Based on the data retrieved from the survey, we are able to compare simulation game with traditional learning methods in terms of subjective effectiveness, difficulty and student preference. We find evidence that game-based learning is more effective, easier to grasp, and more preferred by students than traditional learning methods. We also find evidence that extrinsic motivation (e.g., monetary incentives) affect the effectiveness of gamification in higher education, consistent with existing literature.
\end{abstract}

Index Terms-Game-based learning, simulation game, pedagogy, tertiary education.

\section{INTRODUCTION}

In the past decade a new generation, often referred to as Generation Z, has started tertiary education, and the demand for new adaptive learning methods is growing. Members of Generation $\mathrm{Z}$ use the internet and social media frequently as it becomes part of their life and socialization. One major trait of the members of Generation $\mathrm{Z}$ is the decreased ability to pay constant attention. Game-based learning pedagogy has received widespread attention in recent years, due to its conceivable potential in adapting to the evolving needs from the "Net Generation", or "digital natives" [1]. Previous research has highlighted the merits of gamification theory in handling the specific needs of the before mentioned social group [2]. Learners of today prefer multiple streams of information, frequent and quick interaction with content, technological and collaborative experiences that exhibit clear goals, enhance motivation, and involve authentic activities [1] [3], [4]. It is argued that gamification can improve learning by dividing the learning process into smaller sections and providing instant positive reinforcements. While traditional

Manuscript received September 10, 2015; revised November 25, 2015.

Ding Ding and Yinghui Yu are with the Financial Programme, School of Business, SIM University, 461 Clementi Road, 599491 Singapore (e-mail: dingding@unisim.edu.sg, yhyu@unisim.edu.sg).

Chong Guan is with the Marketing Programme, School of Business, SIM University, 461 Clementi Road, 599491 Singapore (e-mail: guanchong@unisim.edu.sg). modes of teaching find it increasingly challenging to engage and motivate learners, well-designed simulation games arguably provide an opportunity for learners to apply acquired knowledge and to experiment and get feedback in the form of certain outcomes or rewards, which enhance their practical experiences in a "simulated virtual world". They also provide problem solving situations where creativity can be encouraged.

However, due to difficulties in defining, constructing and measuring complex variables as well as the subsequent results, rigorous empirical research on the effectiveness of gamification in education or game-based learning has been limited. In practice, game-based learning has mostly been implemented for children. In the current research, we investigate the effectiveness of game-based learning as an instructional strategy for higher education. Particularly, we compare simulation game with traditional learning methods in terms of subjective effectiveness, level of difficulty and student preference. We proposed that game-based learning is more effective and that students would prefer simulation games to traditional learning methods. We also explore whether extrinsic motivation (e.g., monetary incentives) affect the effectiveness of gamification in higher education.

\section{LITERATURE REVIEW AND HYPOTHESIS DEVELOPMENT}

\section{A. Concept of Games}

One of the most widely adopted definitions of gamification was proposed by Deterding et al. [5], who define gamification as "the use of game design elements in nongame contexts". Over the years, the gamification concept has been successfully applied to a variety of fields such as education [2], idea competitions [6], citizen science [7] and marketing [8].

\section{B. Psychology behind Games}

Gamification facilitates learning through increased attention spans and the added element of fun during the interaction and learning process. In addition, game elements also provide many technical options for language independence and for adequate game challenges based on skill levels.

The basic principle behind games is to create motivation by fun, which leads to happiness [9]. Well known psychological approaches like Maslow's hierarchy of needs, the ERG theory (Existence, Relatedness and Growth) of Alderfer [10], the Goal-setting-theory of Locke and Latham [11], the Flow-theory of Csikszentmihalyi [12], the Balance-theory of Adams [13] and the Self-determination theory of Deci and 
Ryan [14] are some of the many scientific theories that try to explain why and how the motivation of people works. In relation to the gaming context of motivation, Radoff published 42 so called FUNdamentals [15]. The concept is about how fun is created. For example, one of them is "Competition": People enjoy the sense of accomplishment that comes from winning. However, not every FUNdamental creates motivation for everyone.

It can be distinguished between two basic kinds of motivation: intrinsic and extrinsic. Intrinsic motivation is defined as "doing of an activity for its inherent satisfactions" whereas the extrinsic one refers to an activity that is done "in order to attain some separable outcome" [16]. Reiss developed a list of 16 intrinsic motivators [17], which capture what individuals are striving for and what are really important to them. When designing gamified experiences, it is not recommended by Rodrigo to apply external incentives like rewards or points because it will hinder the intrinsic motivation for skilling the inner energetic power of the activity [18].

\section{Potential of Games in the Context of Tertiary Teaching}

It is widely appreciated that games offer the chance to improve the motivation of students, support group work, train communication skills and give opportunities for experimenting in safe environments. Through the integration of game or game elements, the learning effect of students can be increased.

There were a number of previous studies in which game elements were included into university courses [19]. Points and levels served for displaying progress and providing feedback. Leaderboards, challenges and badges were used as game mechanics in order to create autonomy for the students. In these studies the authors indicate that with the game elements the lecture attendance (the considered course provided optional attendance), number of downloads of lecture slides and the number of posts on the course's forums increased. The students participated more; they were more proactive in the forums (students replied five times more to posts and initiated about eight times more threads) and paid more attention to the lectures' slides which indicates a deeper engagement. Students' feedback showed a higher motivation and interest than comparable classes, and the participation and performance of the students increased. Furthermore the authors stated that grade differences between students seemed to decrease.

Coller and Shernoff [20] published in 2009 a preliminary study where the student engagement was measured after redesigning an undergraduate mechanical engineering curriculum. All assignments and learning experiences were built around a video/computer game in the sense that students got in charge of programming a computer program in order to race a simulated car around a track. The author's conclusion is that students experience higher intellectual intensity. When working with the developed video game, the participating students reported greater levels of challenges and concentration on the one hand, and enjoyment and interest on the other. Students felt active and interested, possibly because goals were clear and feedback about performance was immediate.
Based on the limited studies on game-based learning in higher education, it seems that games have a great potential in motivating and engaging learners and may enhance the level of intensity of intellectual activities in tertiary education. Therefore, in this research, we intend to find out whether this is true and how effective the game-based learning is in motivating and engaging students compared with traditional learning methods.

\section{The Gamification Learning Theory}

Gamification learning theory framed a new, innovative approach which roots in previous learning theories in some elements, and used a completely new perspective in others. Some of the major concepts and theories of learning include behaviourist theories, cognitive psychology and connective learning theory. See Table I for a summary of gamification learning theory.

TABLE I: A SUMMARY OF GAMIFICATION LEARNING THEORY

\begin{tabular}{|c|c|}
\hline $\begin{array}{l}\text { Components of } \\
\text { learning }\end{array}$ & ב-Gamification \\
\hline $\begin{array}{l}\text { The learner } \\
\text { Motivation }\end{array}$ & $\begin{array}{l}\text { Conscious individual } \\
\text { Intrinsic }\end{array}$ \\
\hline Knowledge & Internal/external \\
\hline The learning process & Systematic personal processing \\
\hline $\begin{array}{l}\text { The teaching focuses } \\
\text { on }\end{array}$ & $\begin{array}{c}\text { The environment and the cognitive process of } \\
\text { learners }\end{array}$ \\
\hline Engagement & Group-based \\
\hline $\begin{array}{l}\text { The learning path is } \\
\text { guided by }\end{array}$ & $\begin{array}{l}\text { The teacher (establishes different paths), and the } \\
\text { learner (chooses one path) }\end{array}$ \\
\hline The attitude of teacher & Proactive \\
\hline The attitude of learner & Proactive \\
\hline Feedback & Group-based \\
\hline
\end{tabular}

Gamification has more common elements with the behaviourist learning theory (superiority of positive reinforcements, small step-by-step tasks, immediate feedback, and progressive challenges) than with all the other major concepts. First of all, gamification as a learning theory uses community-based evaluation system and reinforcement which strongly differs from the previous theories except the connectivist concept. The second element is that gamification is capable of handling diversified learning paths, as the emphasis is on the small achievements, and not on the links between these achievements, so multiply paths can be constructed to reach the main goal based on the attitude, skills and other characteristics of the learners. This attribute of the theory should be appreciated more and more as the learning groups are getting increasingly diversified. The third but not least important element is that gamification considers the visual dimension of the learning process very important, especially the visualization of the advancement in the learning process and the chosen learning path. Therefore, we have the following hypotheses:

H1: Game-based learning is more effective than traditional learning methods.

H2: Students prefer Game-based learning to traditional learning methods.

\section{METHODS}

The objective of the study is to explore the effectiveness of 
gamification in learning. Given the emergent nature of the research problem, we adopted semi-structured personal-administered surveys as data collection tools. An online stock trading simulation game was introduced as part of the final assessments into one of the undergraduate finance courses in a major university in Singapore for a group of part-time students. The selected simulation game is based on a real trading system and is directly related to the course learning objectives (e.g., a stock investing simulator for the Equity Securities course). The trading game started at the beginning of the course and lasted throughout the course period. While participating in the online game at their own time, students attended 3-hour face-to-face seminars once a week for six weeks. At the end of the course, their performance in the trading game was evaluated and counted for five percent in their final grade. Students were invited to participate in a survey on their experience about the course after the course is completed. Among a total of 67 students in the course, 34 responded to the survey, with a response rate of $50.7 \%$.

In the survey, participants were asked about the amount of time they spent on course materials and the simulation trading game, respectively. The questionnaire also contains the measurement scales of the effectiveness of course materials and the game, how difficult they find them to be, the effectiveness of the cash award and demographics. The subjective effectiveness of both course materials and the simulation game is measured by how helpful and engaging the participants find them to be and how effective they are in helping the participants' understanding and building up their confidence in the course on a 7 points likert-scale ranging from "strongly disagree" to "strongly agree". The perceived difficulty and attitude towards cash incentives are measured by single item 7 points likert-scale ranging from "strongly disagree" to "strongly agree". Student preference of learning are measured by 7 points semantic differential scales ranging from "strongly prefer traditional method" to "strongly prefer game-based method". They were also asked on a 7 points semantic differential scale whether they find the simulation game "much less appealing", "much more appealing" or anywhere in between. Each test session will last for approximately 15 minutes.

The survey participants were $29.6 \%$ women $(n=10)$ and $70.4 \%$ men $(n=24)$ spanning 24 to 41 years of age. The findings from the survey are presents in the next section.

\section{RESULTS AND DISCUSSION}

\section{A. Results on the Effectiveness of Course Materials and the Simulation Game}

TABLE II: SCALE CONSTRUCT RELIABILITY

\begin{tabular}{lcc}
\hline \hline \multicolumn{1}{c}{ Constructs } & $\begin{array}{c}\text { Cronbach's } \\
\text { Alpha }\end{array}$ & $\begin{array}{c}\text { Number of } \\
\text { Items }\end{array}$ \\
\hline Effectiveness of Course Materials & 0.897 & 4 \\
Effectiveness of Simulation Game & 0.817 & 4 \\
\hline \hline
\end{tabular}

Internal consistency reliability analysis was used to assess the reliability of the subjective effectiveness scales on course materials and the simulation game. As shown in Table 2, Cronbach's Alphas for all three constructs are considered acceptable (Cronbach's alpha $>0.8$ ) according to reliability guidelines by DeVellis [21]. Subsequently, the arithmetic means of the four items are used to represent each of the construct, respectively.

TABLE III: COMPARISON OF THE MEAN EFFECTIVENESS AND DIFFICULTY OF COURSE MATERIALS AND THE SiMULATION GAME

\begin{tabular}{ccc}
\hline & Effectiveness & Difficulty \\
\hline Course Materials & 4.765 & 4.765 \\
Simulation Game & 4.801 & 4.147 \\
\hline \hline
\end{tabular}

We first conducted one sample t-test on the perceived effectiveness of course materials and simulation game against a neutral value " 4 " on a 7 point likert scale. Results show that participants perceive both course materials and the simulation game to be effective, with mean scores significantly higher than $4(p=0.000<0.05)$.

Subsequently, we conducted independent sample t-test to examine the mean difference of the perceived effectiveness and difficulty between course materials and the simulation game. Although there is no significant difference between the mean effectiveness found in the quantitative survey results $(p=0.893>0.05)$, we have observed some improvement in student performance in the course assignments after the simulation game is introduced into the course. The mean assignment score has improved from 75/100 to $79 / 100$, compared with previous year based on similar assignment questions.

TABLE IV: COMMENTS By STUdENTS ON THE SimUlation GAME

\begin{tabular}{lcr}
\hline \hline & Counts & Percentage \\
\hline Get exposure to the real-life stock trading & 20 & $58.82 \%$ \\
\hline $\begin{array}{l}\text { Different approach in assessment interests me } \\
\text { game is engaging }\end{array}$ & 7 & $20.59 \%$ \\
\hline Help me to gain knowledge in stock investment & 6 & $17.65 \%$ \\
\hline Get into the habit of reading up on news updates & 2 & $5.88 \%$ \\
\hline $\begin{array}{l}\text { More training on stock analysis is needed } \\
\text { before the game starts }\end{array}$ & 12 & $35.29 \%$ \\
\hline The game is too short & 17 & $50.00 \%$ \\
\hline \hline
\end{tabular}

On the other hand, more than half of the students in the survey provided additional comments on the simulation game. A summary of the key points from their feedback is shown in Table IV. A majority of the students $(58.82 \%)$ indicated that they liked the game because it provided them with a chance to experience the real trading system and practice their own trading strategy without the fear of making a loss. Some of them $(20.59 \%)$ also indicated that the different approach in assessment is interesting and engaging. Two students specifically mentioned that the game helped them to form the habit of reading up on the news updates to better understand the financial markets. Furthermore, half of them felt that the game is too short, and they would like to have more training on stock analysis to make better decision in their investment. Base on the qualitative comments, it is clearly shown that the majority of the students held a favourable view towards the simulation game and felt it was an effective learning tool which help them to get a taste of the real world.

To summarise, although the quantitative results did not provide direct support for Hypothesis 1 (H1), it is strongly supported by the qualitative data. 
In addition, the result from the right column of Table III also show that participants found the simulation game to be less difficult as compared to the traditional course materials and the result is marginally significant $(p=0.081>0.1)$.

\section{B. Results on the Time Spent on the Simulation Game and Course Materials}

TABLE V: COMPARISON OF THE AVERAGE Time SPENT ON COURSE MATERIALS AND SIMULATION GAME

\begin{tabular}{ccccc}
\hline \hline Total Time & \multicolumn{2}{c}{ Course Materials } & \multicolumn{2}{c}{ Simulation Game } \\
Spent per Week & Frequency & Percent & Frequency & Percent \\
\hline Less than 2 hours & 9 & $26.5 \%$ & 15 & $44.1 \%$ \\
3-4hours & 10 & $29.4 \%$ & 8 & $23.5 \%$ \\
5-6hours & 1 & $2.9 \%$ & 4 & $11.8 \%$ \\
7-8hours & 6 & $17.6 \%$ & 2 & $5.9 \%$ \\
9-10hours & 5 & $14.7 \%$ & 3 & $8.8 \%$ \\
11-12hours & 2 & $5.9 \%$ & 1 & $2.9 \%$ \\
13hours or more & 1 & $2.9 \%$ & 1 & $2.9 \%$ \\
\hline \hline
\end{tabular}

Table $\mathrm{V}$ reports the average time spent on course materials and simulation games. It shows that more than half of the students $(55.9 \%)$ reported spending less than 4 hours per week on reading course materials and close to half of the student $(44.1 \%)$ reported spending less than 2 hours per week on the simulation game. As most students spent rather limited time spent on the simulation game, future research needs consider ways to encourage higher level of student involvements for these educational simulation games to achieve their full potential.

\section{Results on Student Preferred Learning Methods}

When compared with traditional learning methods, more than three quarter of the students $(76.5 \%)$ reported that they found simulation games more appealing. More than half of the students $(64.7 \%)$ prefer simulation games as compared to traditional learning method. The findings are consistent with results from one sample t-test on a neutral value " 4 " on a 7 point semantic differential scale. Both means are significantly greater than 4 with p-values equal to 0.000 and 0.005 , respectively, supporting Hypothesis 2.

\section{Results on Cash Awards in the Simulation Game}

The views towards providing cash awards as incentives for simulation game are rather mixed. About one third of the respondents favor such incentives $(35.3 \%)$, one third of them are neutral about it $(35.3 \%)$ and the remaining one third of the respondents are against such incentives (29.4\%). The results from one sample t-test on a neutral value " 4 " on a 7 point semantic differential scale show that the mean score equals to $4(p=0.422>0.05)$. This is consistent with prior research on extrinsic motivation on games, when extrinsic motivation undermine intrinsic motivation [18].

\section{CONCLUSION AND FUTURE RESEARCH}

In this research we examine the effectiveness of game-based learning as an instructional strategy for higher education. We offer two hypotheses: 1) game-based learning is more effective than traditional learning methods and 2) students prefer Game-based learning to traditional learning methods.
To test these two hypotheses we conduct a semi-structured survey on a group of students who take a finance course where an online stock trading simulation game was involved. Regarding hypothesis 1, we find that students' performance shows some improvement after the simulation game is introduced. Also more than half of the students indicate that the simulation game help them gain real life experience and that they would like more exposure to simulation games if possible. Quantitative tests are also carried out to test if this game-based learning is more effective than traditional learning methods, but the result is not statistically significant. However we believe this is at least partially due to the very limited time students spend on the simulation game. Future search is needed to figure out how to encourage higher level of student involvements, in order for the simulation games to be fully utilised. Regarding hypothesis 2 , we find evidence that game-based learning is more preferred by the students. The result is significant at $1 \%$ level. We are also able to provide supporting evidence to the argument that extrinsic motivation could undermine intrinsic motivation on games, supporting Rodrigo's view.

Our paper complements existing literature and contributes to the understanding of game-based learning and its effectiveness, especially in tertiary education. We expect our results, though preliminary, to provide useful insights for both future research and practice. In future research we expect to expand our dataset in terms of size and demographic coverage. We also look to improve the game design to encourage more involvement from students in order to achieve the game's full potential, as well as providing further evidence to the topic under discussion.

\section{REFERENCES}

[1] R. V. Eck, "Digital game-based learning: It's not just the natives who are restless," EDUCAUSE Review, vol. 41, pp. 17-30, 2006.

[2] G. I. Bíró, "Didactics 2.0: A pedagogical analysis of gamification theory from a comparative perspective with a special view to the components of learning," Procedia - Social and Behavioral Sciences, vol. 141, pp. 148-151, 2014.

[3] J. L. Frand, "The information-age mindset: Changes in students and implications for higher education," EDUCAUSE Review, vol. 35, pp. 14-24, 2000.

[4] D. Oblinger, "Boomers, Gen-Xers and Millennials: Understanding the 'new' students," EDUCAUSE Review, vol. 38, pp. 37-47, 2003.

[5] S. Deterding et al., "Gamification: Toward a definition," in Proc. 2011 Annual Conference on Human Factors in Computing Systems, Vancouver, BC, Canada, 2011, pp. 12-15.

[6] M. Witt et al., "Gamification of online idea competitions : Insights from an explorative case," presented at INFORMATIK 2011, Berlin, Germany, 2011.

[7] F. Khatib et al., "Crystal structure of a monomeric retroviral protease solved by protein folding game players," Nature Structural \& Molecular Biology, vol. 18, pp. 1175-1177, 2011.

[8] G. Zichermann and J. Linder, Game-Based Marketing: Inspire customer Loyalty through Rewards, Challenges, and Contests, Wiley Publishing, 2010.

[9] V. Manrique, Gamification Design, Massive Open Online Course, 2014.

[10] C. P. Alderfer, Existence, Relatedness, and Growth, Human Needs in Organizational Settings, New York: Free Press, 1972.

[11] E. A. Locke and G. P. Latham, "New directions in goal-setting theory," Current Directions in Psychological Science, vol. 15, pp. 265-268, 2006.

[12] M. Csíkszentmihályi, Flow: The Psychology of Optimal Experience, New York: Harper and Row, 1990.

[13] J. S. Adams, Inequality in Social Exchange New York, Academic Press, 1965. 
[14] E. Deci and R. Ryan, Handbook of Self-determination Research, Rochester, NY: University of Rochester Press, 2002.

[15] J. Radoff, Game On: Energize Your Business with Social Media Games, Wiley Publishing, 2011.

[16] R. M. Ryan and E. L. Deci, "Intrinsic and extrinsic motivations: classic definitions and new directions," Contemporary Educational Psychology, vol. 25, pp. 54-67, 2000.

[17] S. Reiss, "Multifaceted nature of intrinsic motivation: The theory of 16 basic desires," Review of General Psychology, vol. 8, pp. 179-193, 2004.

[18] I. Rodrigo, Self Determination Theory. Serious Games, Massive Open Online Course, 2014

[19] G. Barata et al., "Engaging engineering students with gamification: An empirical study," in Proc. 5th International Conference on Games and Virtual Worlds for Serious Applications (VS-Games 2013), Bournemouth, UK, 2013, pp. 85-92.

[20] B. D. Coller and D. J. Shernoff, "Video game-based education in mechanical engineering: A look at student engagement," International Journal of Engineering Education, vol. 25, pp. 308-317, 2009.

[21] R. F. DeVellis, Scale Development, Newbury Park, NJ: Sage Publications, 1991.

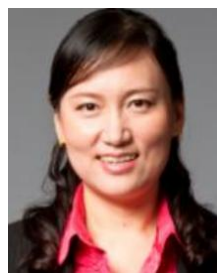

Ding Ding obtained her $\mathrm{PhD}$ in economics from Nanyang Technological University, Singapore, in 2010. She is a chartered financial analyst (CFA) and a member of the Economics Society of Singapore. She is currently the head of Bs. finance programme in the School of Business at SIM University, Singapore, where she has been a faculty member since 2008 Before joining UniSIM, she had been teaching and doing research in economics at NTU for three years. Dr Ding has developed and taught courses in economics and finance, such as financial instruments and markets, cooperate finance and managerial economics. Her current research interests include international economics, development economics, Chinese economy, capital markets, and monetary policy. She has published book chapters and articles in journals such as North American Journal of Economics and Finance.

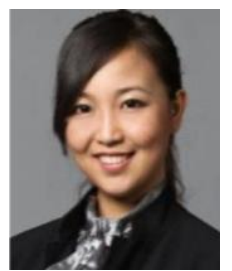

Guan Chong is the head of Marketing Programme and the head of Visual Communication with Business Programme in the School of Business at the SIM University (UniSIM), Singapore, where she has been a faculty member since 2011. Before joining UniSIM, Chong had taught marketing courses at the Nanyang Technological University (NTU), Singapore, for three years. Chong completed her Ph.D. in marketing at Nanyang Business School, NTU, and her undergraduate studies in marketing at Peking University, China. Her research interests lie in the area of online consumer decision making and online social media. Her publications appear in journals including psychology \& marketing, database and International Journal of Virtual Communities and Social Networking. She has also published several book chapters and presented her research at major conferences such as the Informs Marketing Science. She had taught courses in marketing, including research methods, multivariate analysis, marketing and case studies in marketing management.

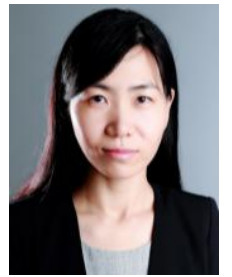

Yu Yinghui obtained her $\mathrm{PhD}$ in finance from University of Hong Kong, China, in 2006.

She is currently a senior lecturer of finance programme in the School of Business at the SIM University, Singapore. Before joining SIM University, she was an option trader at a multinational investment bank for over seven years. She is a CFA® charterholder and she employs her first-hand experience from finance industry in teaching, designing and implementing simulated games for finance courses at SIM University.

Dr Yu's research interests lie in asset pricing, derivatives, risk management, and market microstructure. Her research has been published in finance journals including the prestigious Journal of Finance. 